\title{
Ash Products and Their Economic Profitability
}

\author{
H. Rasmusson*, S. Sarenbo and T. Claesson
}

School of Natural Sciences, University of Linnaeus - Barlastgatan 11, SE-39182, Kalmar, Sweden

\begin{abstract}
Sustainable whole-tree harvesting practice requires that nutrient removal from the forest is compensated. Wood ashes contain all the nutrients, except for nitrogen, that are found in unburned fuel and can also increase soil $\mathrm{pH}$, which makes ash recycling a natural way to stabilize the nutrient balance and counteract the acidification of forest soils that occurs due to intensive forest management. Several methods for processing ashes into spreadable products have been developed. The aim of this paper is to compare these methods. The study mainly focused on an economic evaluation of production, transportation and the spreading of self-hardened ash, ash pellets and ash granules. Self-hardened ash is generally considered to be the cheapest alternative to manufactured ash products, but these results imply that the most cost effective alternative is ash pellets. Around $27 \%$ of total costs could be earned from recycling the ash by producing pellets and $8 \%$ if granules are produced instead of self-hardened ash. This partly depends on the higher density of the pellets and granules and a significant reduction in the number of transportation operations. The reduction in transportation operations and diesel consumption also has major environmental benefits. Furthermore, it is more efficient to produce granules and pellets than it is to produce self-hardened ash and it is also easier to produce a reliable product of an appropriate size, shape and texture for a market that has well defined requirements.
\end{abstract}

Keywords: Ash recycling, ash products, economic valuation.

\section{INTRODUCTION}

Whole-tree harvesting has increased significantly (removal of whole trees, not only the stem wood) leading to a loss of nutrients and acid-buffering substances in forest soils. The shortage of nutrients may, in turn, lead to reduced tree growth and have negative effects on runoff water $[1,2]$. Wood ash is a concentrate of the nutrients found in unburned trees, except for nitrogen $(\mathrm{N})$. The ash also has a high $\mathrm{pH}$, resulting in a liming effect when spread on soil [3]. The whole concept of ash recycling might seem clear and logical, an environmental disposal solution and the missing link in an ecological cycle. However, the $\mathrm{pH}$ of untreated ash is very high and can severely damage the soil and vegetation [4]. Therefore, the ash must be treated by mixing it with water so that the calcium oxide $(\mathrm{CaO})$ reacts with the water and forms the more stable compound, calcium hydroxide $\left(\mathrm{Ca}(\mathrm{OH})_{2}\right)$, which has a lower $\mathrm{pH}$ of, around 10 (Equation 1). The next reaction in the process is where $\mathrm{CaCO}_{3}$ precipitates from $\mathrm{Ca}(\mathrm{OH})_{2}$ in the presence of $\mathrm{CO}_{2}$ [5] (Equation 2).

$\mathrm{CaO}+\mathrm{H}_{2} \mathrm{O} \leftrightarrow \mathrm{Ca}(\mathrm{OH})_{2}$

$\mathrm{Ca}(\mathrm{OH})_{2}+\mathrm{CO}_{2} \leftrightarrow \mathrm{CaCO}_{3}+\mathrm{H}_{2} \mathrm{O}$

In addition to chemical treatment, the ash has to be physically converted into a material that is easy to load, transport and spread. Three common techniques for converting ashes are self-hardening, pelletization and granulation. Self-hardening is a process whereby the ash is mixed with water by a mixing screw or pan mixer in the ash silo at a

*Address correspondence to this author at the School of Natural Sciences, University of Linnaeus - Barlastgatan 11, SE-39182, Kalmar, Sweden; Tel: +46 480447327; E-mail: helene.rasmusson@lnu.se heating plant or an industry, which creates excess heat. It is then transported to and spread on a paved surface in loaf shaped piles where it is allowed to self-harden for 3-6 months. To improve the carbonation and agglomeration process, the pile is compacted and mixed by wheel loaders. This procedure is repeated several times so that carbonation can take place throughout the whole pile [6]. The ash is then crushed and sieved, resulting in a product with a size ranging from fine dust to agglomerates of several $\mathrm{cm}$ in size with a density of approximately $0.75 \mathrm{~kg} / 1$ [7]. The disadvantage of this technique is the varying degree of carbonation within the pile, which partly depends on the difficulties surrounding the management of the mixing operations. This might result in ash with a high reactivity and high $\mathrm{pH}$, which can cause injury to vegetation if spread on forest soils [8]. The carbonation process is also temperature dependent, so storing the pile outdoors runs the risk of such reactions not to proceed to completion and there is also the risk that the easily soluble compounds may leak into surrounding soil and water [9].

Ash pellets can be produced by compaction where the wetted ash paste is compacted into strings by a press cylinder with grooves of a certain width. The strings are then cut to the desired length. The pelletization equipment can be builtinto a container equipped with a set of controls as shown by Windelhed [10]. The apparatus should be able to produce about 5-10 tons of pellets/day. When the pelletization process is finished, the pellets have to dry for about 1 month if self-dried at room temperature [10]. Four different pellet drying techniques have been studied [11]: drying at room temperature, drying by hot air $\left(60\right.$ and $\left.130{ }^{\circ} \mathrm{C}\right)$, and drying by flue gas. Drying granules using flue gas has also been tested in a flue gas simulator [12]. The flue gas drying resulted in 
the lowest $\mathrm{pH}$ and the lowest electric conductivity of the pellets, which is considered advantageous when the product is to be spread in the forest. Ash pellets also have a slow leaching rate and a density of $0.98 \mathrm{~kg} / 1$ [13].

Ash granules are formed by rolling moistened ash in a drum- or disc mixer. Because granulation in a drum- or a disc produces quite large granules, the material has to be sieved in order to produce a desired particle size distribution with granules having a density of $1.0 \mathrm{~kg} / \mathrm{l}$. A binder may be needed to strengthen the granules, usually limestone, dolomite [3], green liquor sludge [14] or cement [15]. Granules have the slowest leaching rate of all the ash products, which is beneficial because it provides a more even and continuous supply of nutrients to the vegetation over a long period of time [16].

Granule production can be performed using cement mixers, with or without knives built-in. They are readily available machines, simple to use and time effective. Alternative, cylindrical containers with shovels anchored to a rotating axel can be used to achieve a homogenous result or rotating disc/drum granulators can be used [17]. Intensive mixers, for example the Eirich mixer from Germany, are filled with ash and water and a high speed drum rotates in order to form perfectly round granules [13, 18].

There are no specific regulations concerning the particle size distribution of ash products that are destined for recycling in Sweden, but the Swedish Forest Agency recommends that their reactivity test should be performed on ash products $<4 \mathrm{~mm}$ in size. Practical spreading experiments in Finland revealed that $>6 \mathrm{~mm}$ sized particles were spread most evenly when applied to forest soils (Mikko Räisänen, personal communication).

Kalmar Energi AB is a Swedish company that runs two heating plants; "Draken" (41. 64 GWh heat production in 2011) and "Moskogen" (136. 4 GWh electricity and 384. 1 GWh heat production in 2011) producing nearly 3000 tons of wood fly ash annually as a byproduct of combustion. The Moskogen heat and power plant is new and became fully operational in 2009. Several studies concerning combustion residues from "Draken" have been performed previously; [3, $5,11-13,19-23]$. There is also fully automated equipment to pelletize the fly ash, but the equipment is currently not in use. The fly ash from the Moskogen heat and power plant is, instead, processed by self-hardening and the final product is spread onto the forest soil. The ash is transported and processed by an entrepreneur responsible for spreading the ash.

The objective of this study was to investigate whether self-hardening is the most economical way to manage the byproducts of combustion for recycling. Every step of the ash recycling chain, from the production of the ash at the heating plant until the ash is spread on the forest floor, was considered.

\section{MATERIALS AND METHODOLOGY}

The Moskogen heat and power plant was chosen as a model for this economic study where we calculated the production costs of 1500 tons of self-hardened ash, pellets and granules during a six-month period. Information concerning the production costs of ash processing and spreading has been gathered from the literature and by interviewing the personnel at the Moskogen heat and power plant and the entrepreneur handling the ashes. Both quantitative and qualitative aspects of the recycling processes were considered. The economic calculations were performed by using Microsoft Excel software.

\section{RESULTS}

\section{Ash Processing Costs}

The production costs of approximately 1500 tons of selfhardened ash during six months at the Moskogen heat and power plant include the costs for the $1300 \mathrm{~m}^{2}$ paved surface, renting and use of the wheel loaders $(105 € / h)$, as well as the crushing and sieving equipment. Management of the ash pile over 3-6 months, with mixing/compaction of the ash twice, and the administration fees, were included. The ash has a moisture content of approximately $25 \%$ when it is put in outdoors stored piles for self-hardening. At the Moskogen heat and power plant, the fly ash is collected by an entrepreneur and transported to a disposal site outside the city of Nybro where self-hardening is undertaken (distance $28 \mathrm{~km}$ ). The entrepreneur manage the ash transportation operations at a cost of $107.1 € / \mathrm{h}$. Calculated on the basis of 300 tons of ash and 6. 75 tons of ash/truckload, then 45 trucks are required. This means that the transport costs are $75 €$ and the cost/ton is $11.2 €$ (Table $\mathbf{1}$ ).

Table 1. Production Costs for 1500 Tons of Self-Hardened Ash (€/ton DM)

\begin{tabular}{|l|c|}
\hline Costs Related to Manufacturing of Self-Hardened Ash & €/Ton DM \\
\hline \hline Costs associated with the paved surface & 2.3 \\
\hline $\begin{array}{l}\text { Management of the ash pile during the } \\
\text { self-hardening phase }\end{array}$ & 3.5 \\
\hline Crushing and sieving & 5.8 \\
\hline Administration fee & 5.8 \\
\hline $\begin{array}{l}\text { Sum A: Ash production exclusively } \\
\text { handled at the heat and power plant }\end{array}$ & 17.4 \\
\hline $\begin{array}{l}\text { Transportation costs to the storage site; } \\
\text { Moskogen-Nybro (28 km) }\end{array}$ & 6.6 \\
\hline $\begin{array}{l}\text { Sum B: Sum A + Transportation costs to storage } \\
\text { place (28 km) }\end{array}$ & 24 \\
\hline
\end{tabular}

The costs for producing 1500 tons of pellets during six months using a pelletization machine with a production rate of 5-10 tons/hour included the cost of a paved surface of about $375 \mathrm{~m}^{2}$, purchase and maintenance of equipment, operation costs and administration fees. A self-drying system was assumed (Table 2).

The production of 1500 tons of granules during six months using an Eirich intensive mixer running at a production rate of 2 tons/hour results in costs for a paved surface $\left(375 \mathrm{~m}^{2}\right)$, purchase and maintenance of equipment (dosage system with weighing scales, mixers, dispensers and control systems), operational costs and administration fees. If granules larger than 3-4 $\mathrm{mm}$ are produced, a plate is needed. A self-drying system is assumed (Table $\mathbf{3}$ ). 
Table 2. Production Costs for 1500 Tons of Ash Pellets (€/Ton DM)

\begin{tabular}{|l|c|}
\hline \multicolumn{1}{|c|}{ Costs Related to Manufacturing of Ash Pellets } & €/Ton DM \\
\hline \hline Costs associated with the paved surface & 0.6 \\
\hline Equipment (Depreciation period: 10 years) & 2 \\
\hline Operating cost & 2.3 \\
\hline Administration fee & 5.8 \\
\hline Total production costs for ash pellets & 10.7 \\
\hline
\end{tabular}

\section{Transport Costs}

Regardless of the ash processing technique, the ash product must be transported from the heating plant to the forest and that distance was assumed to be 50-52 km for the purpose of this study. At the Nybrogrus AB plant, the transport cost over $50-52 \mathrm{~km}$ with a boogie car and trailer was $8.4 € /$ ton $+25 \%$ sales tax in October 2012. The maximum load is 30 tons or $9 \mathrm{~m}^{3}$, which means that 6.75 tons of self-hardened ash can be loaded per truck. Therefore 45 trucks were required to transport 300 tons of ash products. To transport the same amount of pellets, 34 trucks were required and for granules, 33 trucks were needed. Table 4 presents the transport costs for each respective ash product.

\section{Spreading Costs}

An ordinary forwarder, commonly used for ground spreading of ash, is usually loaded with 8 tons of ash at a time, limited by the volume, not the weight. The selfhardened ash has a density of 0.75 tons $/ \mathrm{m}^{3}$, so the amount of ash loaded in the forwarder is $11 \mathrm{~m}^{3}$. The density of granules is 1.0 tons $/ \mathrm{m}^{3}$ and the density of pellets is $0.98 \mathrm{tons} / \mathrm{m}^{3}$. The amount of granules or pellets loaded are therefore roughly $8.0 \mathrm{~m}^{3}$ which means that 3 tons more ash can be loaded if granules or pellets are used instead of self-hardened ash. The number of rounds needed to spread 300 tons of self-hardened ash is 37.5 , while only 27 rounds are needed to spread the same amount of granules or pellets. This means that $28 \%$ fewer rounds are needed to spread granules or pellets. A forwarder consumes about 0.8 liters fuel $/ \mathrm{km}$ or around 120 liters/day so, $28 \%$ less diesel is consumed by driving 10-11 fewer rounds, which means there is a reduction of $58 €$ in diesel costs/day, calculated using the diesel price in Sweden during October 2012 (1.7€/litre).

Table 3. Production Costs for 1500 Tons of Ash Granules (€/Ton DM)

\begin{tabular}{|l|c|}
\hline Costs Related to the Manufacturing of Ash Granules & €/Ton DM \\
\hline \hline Costs associated with the paved surface & 0.6 \\
\hline Equipment (Depreciation period: 10 years) & 11.7 \\
\hline Operating Cost & 2.3 \\
\hline Administration fee & 5.8 \\
\hline $\begin{array}{l}\text { Total production costs for ash granules } \\
\text { (excluding the plate) }\end{array}$ & 20.4 \\
\hline
\end{tabular}

\section{Summary of Costs}

The differences in total costs between self-hardened ash, granules and pellets are presented in $€ /$ ton DM and a cost comparison for different amounts of each ash product are illustrated in Fig. (1). All relevant economic factors are compiled in Table 4 . It is $27 \%$ cheaper to use pellets instead of self-hardened ash and $8 \%$ cheaper to use granules than self-hardened ash, if the total costs involved in the ash recycling process are taken into account.

\section{DISCUSSION}

The most common method used for processing ash, selfhardening, is not the most economically beneficial choice for the purposes of ash recycling. By producing pellets, the total

Table 4. The Costs of the Ash Products are Compared at Every Part of the Ash Recycling Chain and then Summed and Presented in $€ /$ Ton DM and $€ /$ ha for the Production of 1500 Tons of Ash

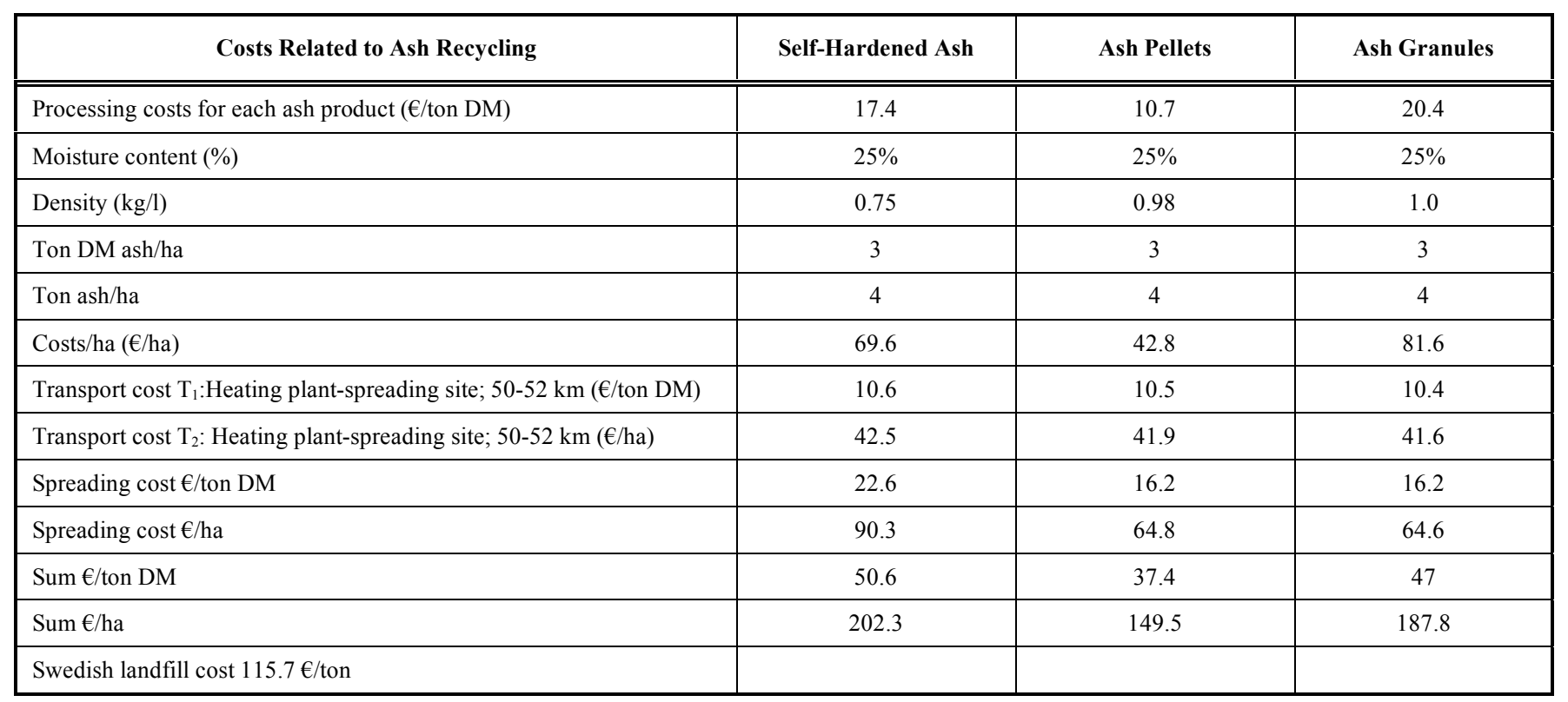




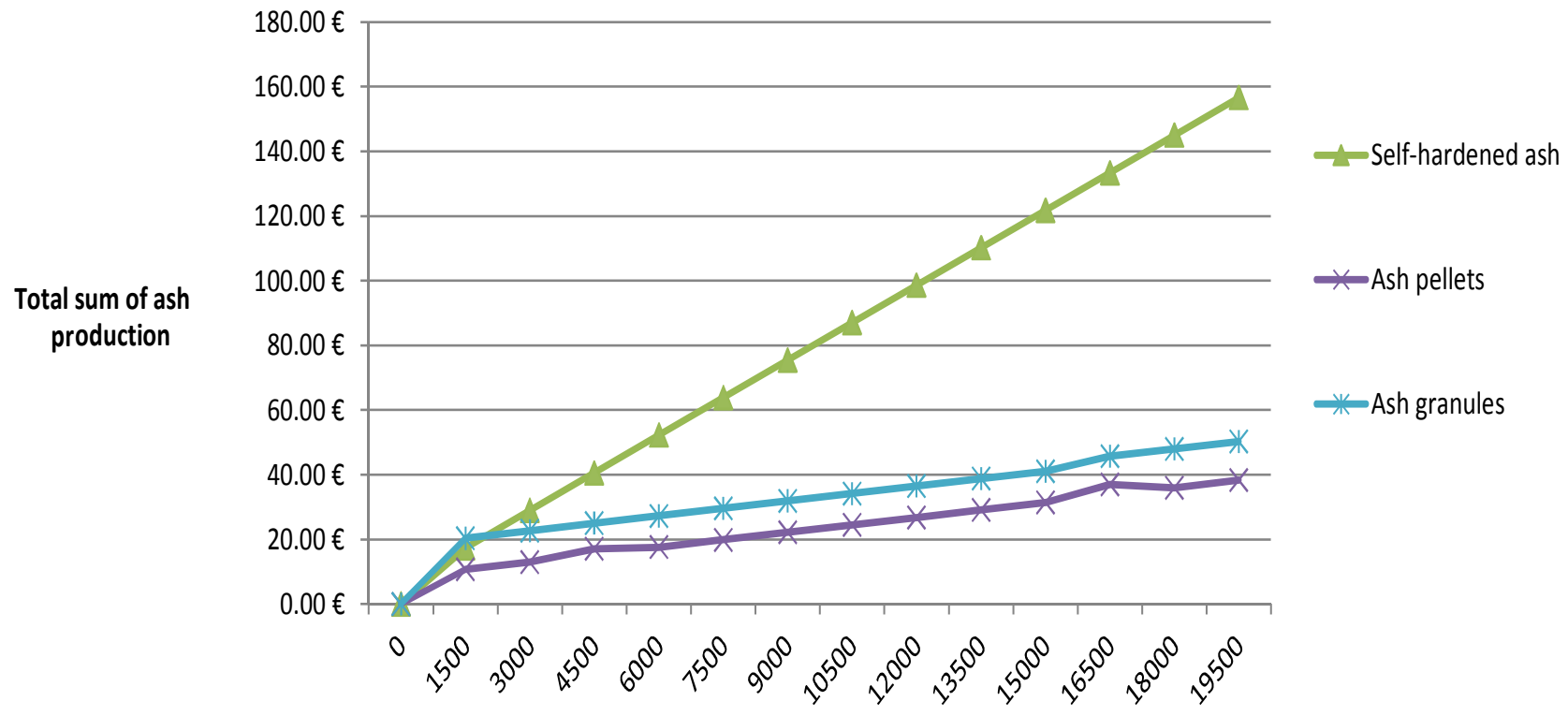

Fig. (1). Production costs for self-hardened ash, pellets and granules relative to the amount of ash produced.

costs for ash recycling could be lowered by $27 \%$ if 1500 tons of ash is produced during six months. If granules are produced, then the total costs could be reduced by $8 \%$ compared to self-hardened ash, if the same amount of ash were produced. The production of self-hardened ash is cheaper than the granules during the first phase because there is no need to purchase expensive granulation equipment. However when it comes to the transportation operations and the spreading phase, granules are the cheapest alternative compared to both self-hardened ash and pellets. The total granule production costs depend on what kind of technique that is used; there are several techniques available and other simpler and cheaper granulation techniques than presented in this work exist. The costs also depend on the quantity of ash product produced. As is illustrated in Fig. (1), the production of self-hardened ash increases exponentially relative to the amount of ash product produced. The large increase in costs is due to the need for a large paved surface in order to produce self-hardened ash. If the amount of self-hardened ash produced is doubled, then the area required to handle the self-hardening is doubled, as is the number of wheel loader operations. This is not the case with pellet or granule production. The surface area needed is not dependent on the amount of pellets or granules produced. Even the transportation operation costs can differ depending on the circumstances. These calculations have been performed from the starting point that all production takes place in the heat and power plant at Moskogen in Kalmar, but currently selfhardening takes place at another site away from the Moskogen heat and power plant, which means that there are large costs for extra transportation operations. The lower costs of using granules or pellets instead of self-hardened ash depend, to a great extent, on the difference in density between the products. On average, $30 \%$ more granules and about $28 \%$ more pellets can be packed for a given weight compared to the self-hardened ash, meaning that the transportation operations and spreading of granules or pellets requires less diesel, which significantly reduces the costs.

\section{CONCLUSIONS}

Unlike what is generally stated about ashes, this study shows that ash pellets are the most cost effective alternative for ash recycling, not the production of self-hardened ash. Even the granules are a cheaper alternative to self-hardened ash and the gap increases relative to the amount of ash produced. With regards to the practical aspects, the granules and pellets have advantages compared to self-hardened ash because of the lower number of transportation operations that comes as a result of the differences in material density. The reduction in diesel consumption also has considerable environmental advantages. The conclusion of this study is that pellets are the most cost effective option but even the granules are a beneficial choice for a more effective, economic and environmentally friendly solution to the ash recycling issue.

\section{CONFLICT OF INTEREST}

The authors confirm that this article content has no conflict of interest.

\section{ACKNOWLEDGEMENTS}

We gratefully acknowledge the financial support for this study from the Swedish Agency for Economic and Regional Growth through the EUs regional fund, the Regional Council of Southern Småland and the following companies; Kalmar Energi $\mathrm{AB}$, Bioenergigruppen i Växjö $\mathrm{AB}$, SÖDRA and VEAB.

\section{REFERENCES}

[1] A. Wall, "Risk analysis of effects of whole-tree harvesting on site productivity", For. Ecol. Manage., vol. 282, pp. 175-184, 2012.

[2] A. Saarsalmi, E. Mälkönen and S. Piirainen, "Effects of wood ash fertilization on forest soil chemical properties", Silva Fenni. vol. 35, no. 3, pp. 355-368, 2001.

[3] S. L. Holmberg, B. Lind and T. Claesson, "Chemical composition and leaching characteristics of granules made of wood ash and dolomite", Environ. Geol., vol. 40, no. 1-2, pp. 1-10, 2000. 
[4] J. Eriksson, "Dissolution of hardened wood ashes in forest soils: studies in a column experiment", Scand. J. For. Res. Supl., vol. 2, pp. 23-32, 1998

[5] S. L. Holmberg and T. Claesson, "Mineralogy of granulated wood ash from a heating plant in Kalmar, Sweden”, Environ. Geol., vol. 40, no. 7, pp. 820-828, 2001.

[6] B-M. Steenari and O. Lindqvist, "Stabilization of biomass fuel ashes for recycling to forest soil", Biomass. Bioenerg., vol. 13, pp. 39-55, 1997

[7] L. Tegnér, K. Widegren-Dafgård and K. Ståhl, "Calculation of chemical stability of bio-fuel ash" (In Swedish), A report by Sydkraft, NUTEK \& Vattenfall, Sweden, 1997.

[8] I. Lindström and A. Nilsson," Self-hardening- Technique for transforming wood fuel ash to forest fertilizer" (In Swedish), Swedish Energy Agency, 1998.

[9] I. Lindström, "Identification and synthesis of technology and logistics systems" (In Swedish), NUTEK, Raport R, 1996:14, 1996.

[10] K. Windelhed, "Roll pelleting- Evaluation of a new technique for producing pellets from bioash suitable for forest nutrient" (In Swedish), Sycon Teknikkonsult AB, Värmeforsk Service AB, Sweden, Värmeforskrapport 695, 2000.

[11] S. Sarenbo, P. Mellbo, O. Stålnacke and T. Claesson, "Reactivity and leaching of wood ash pellets dehydrated by hot air and flue gas", Waste Manage., vol. 2, pp. 47-54, 2009.

[12] S. L. Holmberg, T. Claesson, M. Abul-Milh and B-M. Steenari, "Drying of granulated wood ash by flue gas from saw dust and natural gas combustion", Res. Cons. Rec., vol. 38, no. 4, pp. 301316, 2003.

[13] T. Svantesson, "Automated manufacture of fertilizing agglomerates from burnt wood ash", PhD thesis, Lund University, Sweden, 2002.
[14] A-H. Österås, I. Sunnerdahl and M. Greger, "The impact of wood ash and green liquor dregs application on $\mathrm{Ca}, \mathrm{Cu}, \mathrm{Zn}$ and $\mathrm{Cd}$ ", $J$. Water Air Soil Pollut., vol. 166, pp. 17-29, 2005.

[15] L. Högbom and H-Ö. Nohrstedt, "The fate of ${ }^{137} \mathrm{Cs}$ in coniferous forests following the application of wood ash", Sci. Total Environ., vol. 280, pp. 133-141, 2001

[16] C. Nilsson and B-M. Steenari, "Characterization and treatment of wood ash" (In Swedish), NUTEK R, vol. 15, 1996.

[17] A. Nilsson, "Techniques for ash processing" (In Swedish), NUTEK Rapport R, vol. 32, 1993.

[18] M. Rhodes, "Principles of powder technology", Wiley: Chichester, 1990

[19] T. Svantesson, "Automated manufacture of fertilizing granules from burnt wood ash", $\mathrm{PhD}$ thesis, Lund University, Sweden, 2000.

[20] S. L. Holmberg and T. Claesson, "Limestone and dolomite powder as binders for wood ash agglomeration", Bull. Eng. Geo. Environ., vol. 63, no. 3, pp. 191-207, 2004.

[21] P. Mellbo, S. Sarenbo, O. Stålnacke and T. Claesson, "Leaching of wood ash products aimed for spreading in forest floors - Influence of method and L/S ratio", Waste Manag. vol. 28, no. 11, pp. 22352244, 2008.

[22] O. Stålnacke, S. Sarenbo and B. Zethræus, "Experimental method to verify the real residence-time distribution and temperature in MSW-plants", IFRF Combustion J., Article Nr 200802, ISSN 1562-479X, 2008.

[23] O. Stålnacke and B. Zethræus, "Emissions performance of a 40 MW pulverised wood fired boiler", IFRF Combustion J., Article $\mathrm{Nr}$ 20090, ISSN 1562-479X, 2009. 